\title{
Reducing Compressibility of the Expansive Soil by Microbiological-Induced Calcium Carbonate Precipitation
}

\author{
Xiaobing Li, ${ }^{1}$ Chunshun Zhang $\mathbb{D},{ }^{2}$ Hongbin Xiao $\mathbb{D}^{1},{ }^{1}$ Weichang Jiang, ${ }^{1}$ Junfeng Qian $\mathbb{D},{ }^{1,3}$ \\ and Zixiang $\mathbf{L i}^{1}$ \\ ${ }^{1}$ Institute of Geotechnical Engineering, Central South University of Forestry and Technology, Changsha 410004, China \\ ${ }^{2}$ Department of Civil Engineering, Monash University, Clayton, VIC 3800, Australia \\ ${ }^{3}$ Technology R\&D Center, Hubei Road \& Bridge Group Co., Wuhan 430056, China
}

Correspondence should be addressed to Chunshun Zhang; ivan.zhang@monash.edu and Hongbin Xiao; t20090169@csuft.edu.cn

Received 12 August 2020; Accepted 19 January 2021; Published 10 February 2021

Academic Editor: Songtao Lv

Copyright (c) 2021 Xiaobing Li et al. This is an open access article distributed under the Creative Commons Attribution License, which permits unrestricted use, distribution, and reproduction in any medium, provided the original work is properly cited.

Most of the research studies on the improvement of expansive soils are focused on reducing their expansive properties; however, there are few studies on the impact of the soil compressibility after the improvement. In this paper, through indoor high-pressure consolidation tests, the recent microbial-induced calcium carbonate precipitation (MICP) technology is studied to improve the compression characteristics of the expansive soil. The significant effect of different microbial concentrations (achieved by different number of treatments) on the compression deformation is revealed with the hyperbolic function that involves two parameters with clear physical meanings. In particular, after 6 times of treatment with the microbial solution, the compression characteristics of the expansive soil reach the best improvement effect; continuing to increase the number of microbial treatments is, otherwise, not conducive to improving the soil compression performance. Also, a dramatical increase of the structural strength of the microbial-treated expansive soil is presented and investigated. Moreover, we performed a scanning electron microscope (SEM) experiment and confirmed the existence of crystals due to mineralization. This study shows that MICP is an effective and environmentally friendly means of reducing the compressibility of the expansive soil.

\section{Introduction}

Expansive soil is a special kind of catastrophic clay and is widely distributed in the world. In order to use land resources rationally, it is usually necessary to improve the poor engineering characteristics of the soil so that the expansive soil can be used to fill the embankment or the subgrade of a building.

One way is to add a certain amount of inorganic materials such as lime, cement, or fly ash for chemical and physical improvement of the expansive soil $[1,2]$. For example, Phanikumar and Nagaraju [3] proposed a comparative study of an expansive clay using fly ash and rice husk ash. The test results showed that liquid limit, plasticity index, and free swell index decreased significantly with increasing fly ash and rice husk ash contents. However, coefficient of permeability increased with additive content. Bian et al. [4] studied the physical and mechanical characteristics of lime-modified expansive soil through experimental research and found that, as the ash content increases, the cohesion, internal friction angle, and CBR value of the expansive soil increase; after that, they proposed that the CBR and direct shear strength of 7-day cured lime soil could be adopted to determine the best ash content. Voottipruex and Jamsawang [5] analyzed the swelling and strength characteristics of the expansive soil using cement and fly ash, and then they concluded that the swelling percentage can predict the swelling and strength characteristics of the soil. Though these are useful findings, there are some limitations, such as the uniform mixture of lime and expansive soil is difficult to achieve, long period, high construction cost, and environmental pollution due to the mixing process. Therefore, it is necessary to find a new, environmentally friendly, and more applicable alternative method for improving the expansive soil. 
Alternatively, microbially induced carbonate precipitation (MICP) technology is an emerging technology that has developed rapidly in recent years and has been widely used in many fields. This new technology has also been used in geotechnical engineering and gradually formed a new microbial geotechnical technology with great significance in soil mechanics and engineering applications [6-14]. The mechanism of MICP technology is to catalyze the hydrolysis of urea through urease generated during microbial metabolism; this process generates ammonia and carbon dioxide that are dissolved in water in an alkaline environment to generate ammonium and carbonate ions; once these carbonate ions meet sufficient calcium ions, calcium carbonate precipitates with gelling effect are generated. This calcium carbonate precipitation can not only fill the pores between the soil particles but also form glue on the surface of the soil particles to make the soil particles adhere to each other. When calcium carbonate precipitates and solidifies, a relatively high-strength calcium carbonate crystals are formed, which improve many engineering properties of the soil [15-17]. The chemical reaction process of calcium carbonate precipitation induced by microorganisms can be simplified as shown in the following:

$$
\begin{gathered}
\mathrm{CO}\left(\mathrm{NH}_{2}\right)_{2}+\mathrm{H}_{2} \mathrm{O} \longrightarrow \mathrm{CO}_{2}+2 \mathrm{NH}_{3} \\
2 \mathrm{NH}_{3}+2 \mathrm{H}_{2} \mathrm{O} \leftrightarrow 2 \mathrm{NH}_{4}^{+}+2 \mathrm{OH}^{-} \\
\mathrm{CO}_{2}+\mathrm{OH}^{-} \longrightarrow \mathrm{HCO}_{3}^{-} \\
\mathrm{Ca}^{2+}+\mathrm{OH}^{-}+\mathrm{HCO}_{3}^{-} \longrightarrow \mathrm{CaCO}_{3}+\mathrm{H}_{2} \mathrm{O}
\end{gathered}
$$

Whiffin [18] used Bacillus pasteurii to induce calcium carbonate to precipitate and cement sand particles, thereby improving the shear strength of the sand; also, the solidification effect of Bacillus pasteurii and urease-producing strains isolated from the soil was compared; thereafter, the effects of calcium ion concentration and grouting methods on the strength of microbially reinforced sand were studied. His experimental results showed that the uniaxial compressive strength of the sand sample treated by Bacillus pasteurii was as high as $5.8 \mathrm{MPa}$. Sharaky et al. [19] found that Sporosarcina pasteurii plays an important role in the sand biocementation process, and the research results showed that the compressive strength of sandy soil increased due to the precipitation of calcium carbonate by the bacterial activity. Through experimental research, Liu et al. [20] systematically analyzed the strength characteristics of MICP-reinforced sand and proposed a unified strength theory for the reinforcement of calcareous sand. Based on MICP technology, Khaleghi and Rowshanzamir [21] had a comparison study on sandy soil using single and mixed cultures. The research results verified that the mechanical and physical properties of sandy soil with both single and mixed media improved through the MICP, especially the outcome of the mixed medium was much better than that of the single medium. Wang et al. [22] used different treatment cycles of MICP technology to improve the wind erosion resistance of the sand; it showed that the density and wind erosion resistance of the sand increase with the number of treatments, so using MICP technology could reduce and prevent the increase of desertification. Liu [23] analyzed the dynamic characteristics of calcareous sand and its cementation mechanism based on the MICP technology and concluded that, after the MICP treatment, the dynamic strength and resistance to deformation of calcareous sand were improved to a certain extent. Canakci et al. [24] used MICP technology to improve organic soil. The test results indicated that the bacterial treatment increased shear strength and reduced compressibility of the organic soil.

The above application of MICP technology in domestic and international geotechnical engineering has made some preliminary research advances [25-28]. However, the results of the above studies are intended to improve the strength of sandy soils [29-32], and there is little research on the effect of MICP on improving the compressibility of clay, especially expansive soil. Considering the increase in engineering demand in expansive soil areas, this requires a new environmentally friendly and economical method to improve expansive soil. Therefore, we try to apply the emerging MICP technology to study its effect and mechanism on the improvement of expansive soil, focusing on soil compressibility. Through laboratory consolidation tests, the compression characteristics and deformation laws of the expansive soil before and after the MICP improvement are compared and studied.

\section{Soil Samples and Testing Scheme}

2.1. Preparation of Soil Samples. The test soil material was taken from the expansive soil excavated from the ring road engineering in Nanning, Guangxi. According to the code, Test Methods of Soils for Highway Engineering (JTGE 402019), the measured basic physical properties and chemical composition of the soil are shown in Tables 1 and 2, respectively.

According to the free expansion rate in Table 1 and the classification as specified in the code JTGE 40-2019, it can be determined that the soil samples used in the tests are medium expansive soils. The microorganism used in our experimental study is Bacillus pasteurii with strain number ATCC11859, which was purchased through the China National General Microbial Species Collection Management Center (CGMCC). It has high-yielding urease and is widely used Bacillus, which is harmless to humans and the environment.

During the test, the first step was to quickly propagate and cultivate Bacillus pasteurii: the bacteria were taken from the refrigerator, cells were activated, and the culture solution was inoculated on a sterile operation platform. The culture medium used in the test was mainly composed of nutrients such as urea, casein peptone, soy peptone, and sodium chloride. Then, the inoculated culture solution was cultured on a shaker for 48 hours, and then the concentration of the bacterial solution was measured using a spectrophotometer. The concentration of the bacterial solution is usually expressed by the absorbance OD600 value, and it can be used for the test when it is greater than 1.0 [33-36].

The bacterial solution and cementation solution (mixed solution of calcium chloride and urea) were added into the 
TABLE 1: Physical properties of the expansive soil.

\begin{tabular}{lccccccc}
\hline Soil source Natural density $\left(\mathrm{g} / \mathrm{cm}^{2}\right)$ & Max dry density $\left(\mathrm{g} / \mathrm{cm}^{2}\right)$ & $\begin{array}{c}\text { Relative } \\
\text { gravity } \mathrm{G}_{\mathrm{s}}\end{array}$ & $\begin{array}{c}\text { Liquid } \\
\text { limit }(\%)\end{array}$ & $\begin{array}{c}\text { Plastic } \\
\text { limit }(\%)\end{array}$ & $\begin{array}{c}\text { Plastic } \\
\text { index (\%) }\end{array}$ & $\begin{array}{c}\text { Optimum } \\
\text { moisture } \\
\text { content }(\%)\end{array}$ & $\begin{array}{c}\text { Free swelling } \\
\text { rate }(\%)\end{array}$ \\
\hline Nanning & 1.94 & 1.88 & 2.70 & 60.8 & 22.4 & 38.4 & 16.2 \\
\hline
\end{tabular}

TABLE 2: Chemical composition of the expansive soil.

\begin{tabular}{lccccccccc}
\hline $\mathrm{Si}^{4+}(\%)$ & $\mathrm{Al}^{3+}(\%)$ & $\mathrm{Fe}^{3+}(\%)$ & $\mathrm{K}^{+}(\%)$ & $\mathrm{Mg}^{2+}(\%)$ & $\mathrm{Ca}^{2+}(\%)$ & $\mathrm{Ti}^{4+}(\%)$ & $\mathrm{Cu}^{2+}(\%)$ & $\mathrm{S}^{2+}(\%)$ & $\mathrm{Mn}^{2+}(\%)$ \\
\hline 23.5 & 57.6 & 8.9 & 4.2 & 2.3 & 1.6 & 0.9 & 0.7 & 0.2 & 0.1 \\
\hline
\end{tabular}

soil sample at a volume ratio of $1: 1$. The concentration of the cementation solution was determined to be $0.2 \mathrm{M}$ [37]. The concentration of the bacterial solution and cementation solution used in this experiment was found to be the optimum concentration and beneficial to the generation of microorganism mineralization. We collectively refer to bacterial solution and cement solution as treatment solution. During this test, we perform multiple processing on the expansive soil using treatment solution, which can ensure the cumulative concentration of the treatment solution is sufficient and the soil sample is in a plastic state. And the soil samples were subjected to $0,2,4,6$, and 8 treatments, respectively. All soil samples after curing and drying are tested with the optimum moisture content [38-41]. All soil samples are $61.8 \mathrm{~mm}$ in diameter and $20 \mathrm{~mm}$ in height to meet the requirement of the consolidation test.

2.2. Testing Scheme. The consolidation instrument used in the test is a GDG-4S Triplex high-pressure consolidation testing apparatus. Consolidation tests were performed according to code JTGE 40-2019.

First, $1 \mathrm{kPa}$ pressure was applied, and prepressed to ensure that all parts of the consolidation instrument were in close contact. Then, the preload was removed, and the first load was quickly applied. After the first-level load was stabilized for 24 hours, the next-level load was applied, and the total load was divided into eight levels. The load of each level was $12.5 \mathrm{kPa}, 25 \mathrm{kPa}, 50 \mathrm{kPa}, 100 \mathrm{kPa}, 200 \mathrm{kPa}, 300 \mathrm{kPa}$, $400 \mathrm{kPa}$, and $800 \mathrm{kPa}$. During the loading process, the consolidated specimens were wrapped around with a damp cloth to prevent evaporation of water in the soil sample during the long-term loading.

\section{Test Results and Analysis}

3.1. Variation of the Compression Curve. According to the test results, the $e$ - $p$ curves of the expansive soil after microbial improvement (the number of treatments is represented by $x$, which is $2,4,6$, and 8 , respectively) and the untreated expansive soil, as shown in Figure 1.

It can be found from Figure 1 that the initial porosity ratios of the expansive soil samples subjected to different number of times of microorganism treatment are slightly different from those of the untreated microorganism. This is because the amounts of calcium carbonate precipitated in the soil particles after different number of times of microbial

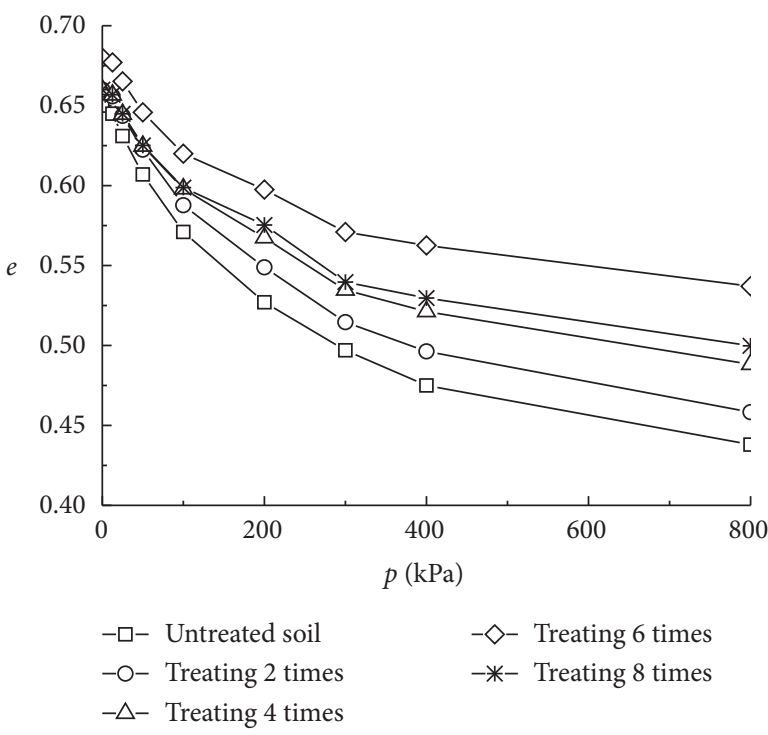

FIgURE 1: $e$ - $p$ curves of the expansive soil.

treatment are different, so the bulk densities of the soil samples changed slightly, although the initial water content of each soil sample is the same.

It can also be found from Figure 1 that the porosity ratios of the expansive soil treated with different number of times of microorganisms decrease with the increase of the consolidation pressure. That is to say, the expansive soil has undergone compression deformation under different consolidation pressures. On the contrary, with the increase of the consolidation pressure, the $e$ - $p$ curves of the expansive soil samples with different number of times of microbial treatment decrease significantly at different rates. Except for the soil samples after 8 times of treatment, the $e$ - $p$ curves of other soil samples become smoother with the increasing number of treatments, that is, the compression coefficient becomes smaller, and the compression modulus becomes larger. This law shows that the compression characteristics of the expansive soil have been improved to varying degrees after microbial treatment; particularly, when the number of treatments is less than six, the more the number of treatments is, the more obvious the compression characteristics improve. Note that when the number of soil modifications reached 8 times, the compression characteristics of the soil samples became significantly worse. This is because during the test, after each microbial treatment, the soil samples were 
air-dried and crushed, which affected the mesostructure of soil particles, resulting in increasing fine particles, some of which might not be sufficiently cemented by the calcium carbonate precipitates. Therefore, in order to ensure the improvement effect of the expansive soil, it is necessary to avoid excessive crushing of the soil sample during the test. In addition, as the number of soil modifications increases, the precipitation efficiency of calcium carbonate between soil particles may decrease [42]. Therefore, we do need to control the number of soil modifications.

When the consolidation pressure is 0 to $400 \mathrm{kPa}$, after the microorganism treatment of $0,2,4,6$, and 8 times, the corresponding reduction ratios of the porosity ratio are $17.5 \%, 16.4 \%, 13.9 \%, 11.7 \%$, and $13.0 \%$, respectively; when the consolidation pressure is further increased from $400 \mathrm{kPa}$ to $800 \mathrm{kPa}$, the corresponding porosity ratios are further reduced to $3.8 \%, 3.7 \%, 3.3 \%, 2.6 \%$, and $3.0 \%$ for the 5 times of treatment. These reductions in porosity ratios under increasing the consolidation pressure are listed in Table 3.

It can be seen from Table 3 that, on the one hand, regardless of whether the expansive soil is processed by the MICP technology, the overall compression characteristics of the soil remain unchanged: at the initial compression stage, the slope of the $e$-p curve is larger, and the amount of soil compression is larger, reflecting the large decrease in soil porosity ratios at low compression levels; when the vertical pressure exceeds $400 \mathrm{kPa}$, the e-p curve tends to be gentle, and the amount of compression of the soil body gradually decreases, reflecting the decrease in the reduction of the porosity ratio of the soil body. This is because when the soil is compressed, the soil particles will rearrange and become densely packed with each other, and also, water and gas in the soil are squeezed out of the pores of the soil. All these contribute to the soil compactness, so the movement of the soil particles becomes more and more difficult, resulting in smaller and smaller compression deformation.

On the other hand, under the same consolidation pressure, the reductions of porosity ratios of the microbially modified expansive soil samples are less than those of the untreated soil sample. As the number of microbial treatments increases, the change of the porosity ratio of the soil decreases first. After the treatment for 6 times, the change of the porosity ratio is the smallest. This evidently confirms the effect of using microorganisms to improve the compressibility of the expansive soil that is related to the number of treatments. In our study, the compressibility of the expansive soil obtained the best improvement after 6 microbial treatments.

3.2. Variation of the Index of Compressibility. According to the test results, the relationships between the coefficient of compressibility, $a_{1-2}, a_{1-2}$ is the compression coefficient of consolidation pressure between $100 \mathrm{kPa}$ and $200 \mathrm{kPa}$, the compression modulus $E_{s}$, and the final compression amount $S_{f}$ of the microbially modified expansive soil are shown in Figures 2 and 3, respectively.

It can be seen from Figure 2 that, after 6 times of microbial solution treatment, the coefficient of compressibility,
TABle 3: Reduction of the void ratio.

\begin{tabular}{lccccc}
\hline$p(\mathrm{kPa})$ & $0(\%)$ & $2(\%)$ & $4(\%)$ & $6(\%)$ & $8(\%)$ \\
\hline $0-400$ & 17.5 & 16.4 & 13.9 & 11.7 & 13.0 \\
$400-800$ & 3.8 & 3.7 & 3.3 & 2.6 & 3.0 \\
\hline
\end{tabular}

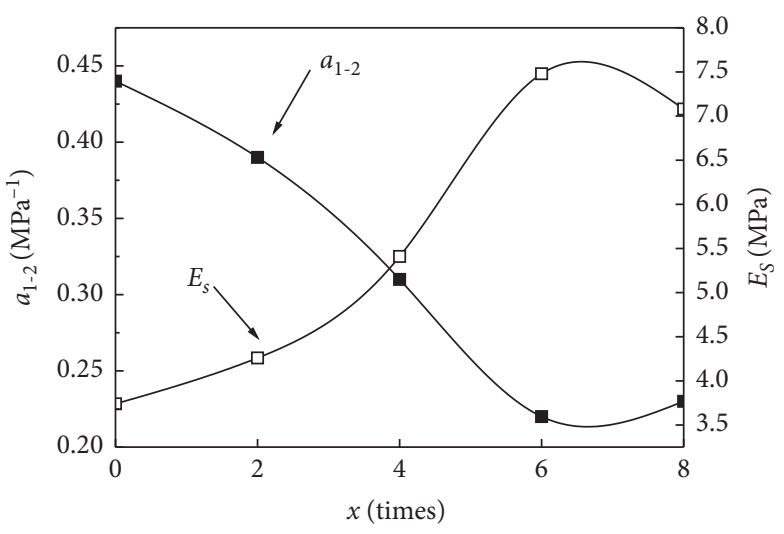

Figure 2: Relation between $a_{1-2}$ or $E_{s}$ and $x$.

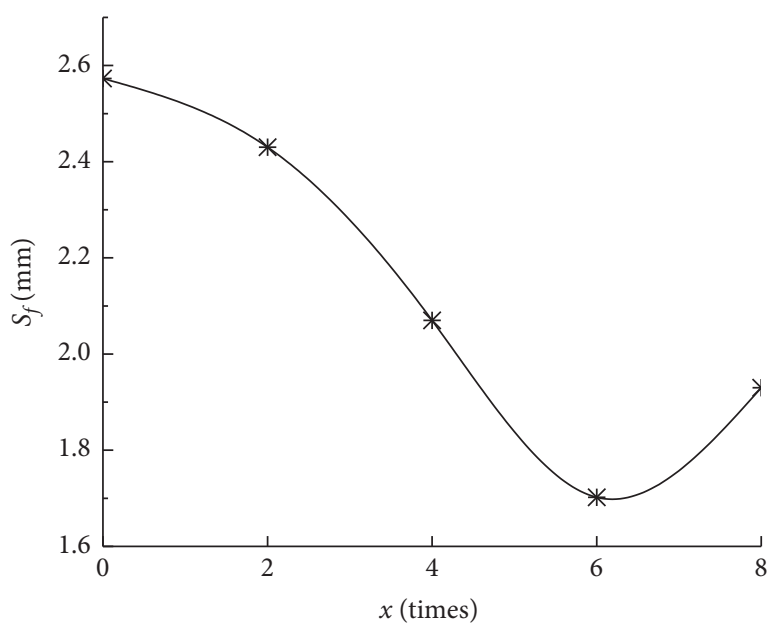

FIgURE 3: Relation between $S_{f}$ and $x$.

$a_{1-2}$, of the expansive soil decreased from $0.44 \mathrm{MPa}^{-1}$ to $0.22 \mathrm{MPa}^{-1}$, and its compression modulus increased from 3.74 MPa to $7.48 \mathrm{MPa}$; the final compression of the soil sample was reduced from $2.57 \mathrm{~mm}$ to $1.70 \mathrm{~mm}$. Both the compression coefficient and the final compression amount of the expansive soil decrease first and then increase with the increase in the number of microbial treatments; the compression coefficient and the final compression amount of the unimproved plain expansive soil are the largest. After 6 times of microbial treatment, both reached the minimum. The expansion modulus of the expansive soil increased first and then decreased with the increase of the number of microbial treatments. The untreated expansive soil has the smallest compression modulus. After 6 times of microbial 
treatment, the expansive soil has the highest compression modulus.

In practical engineering, the compression coefficient $a_{1-2}$ is usually used to judge the compressibility of the soil.

(1) For $a_{1-2} \leq 0.1 \mathrm{MPa}^{-1}$, it is a lowly compressible soil

(2) For $0.1 \mathrm{MPa}^{-1} \leq a_{1-2} \leq 0.5 \mathrm{MPa}^{-1}$, it is a moderately compressible soil

(3) For $a_{1-2} \geq 0.5 \mathrm{MPa}^{-1}$, it is a highly compressible soil

From the above range, it can be known that the untreated expansive soil with $a_{1-2}=0.44 \mathrm{MPa}^{-1}$ is a medium-high compressive soil. After the microbial treatment for 6 times, $a_{1-2}=0.22 \mathrm{MPa}^{-1}$, which is a moderately compressible soil. Therefore, the above results show that the compression characteristics of the expansive soil can be significantly improved by using the MICP technology. The reason is associated with the increase of calcium carbonate precipitation induced by microorganisms. The generation of microorganisms has been confirmed. Through the scanning electron microscope (SEM), as shown in Section 4, a thin layer of calcite covering soil particles was observed. This finding is consistent with that of Islam [43]. Calcium carbonate precipitates not only cement the surface of the soil particles but also fill the pores between the soil particles so that the fine soil particles may form aggregates, serving as an additional skeleton to resist external loads. Therefore, the compression characteristics of the expansive soil are improved, and the amount of compressive deformation is reduced.

On the contrary, the improvement effect of the expansive soil is related to the number of microbial treatments. When the microbial treatment reaches 6 times, the treatment effect reaches the best. When the number of treatments reaches 8 times, the coefficient of compressibility of the expansive soil sample becomes larger, which indicates that when the number of times of treatment with treatment solution is not the more, the better. As the number of treatments increases, the number of times that the expansive soil is crushed (following the processing requirement) also increases, resulting in an increase in fine particles in the soil that might not be sufficiently wrapped by the calcium carbonate precipitates, and thereby a larger coefficient of compressibility. Moreover, as the processing number of times increases, the precipitation efficiency of calcium carbonate between soil particles may reduce. Therefore, in order to achieve the best improvement effect, not only excessive crushing should be avoided but also there is a need to reasonably control the processing number of times during the test.

By processing the test data, the change curves between the coefficient of compressibility, $a$, the compression coefficients at consolidation pressures of $12.5-50 \mathrm{kPa}$, $50-100 \mathrm{kPa}, 100-200 \mathrm{kPa}, 200-400 \mathrm{kPa}$, and $400-800 \mathrm{kPa}$, and the consolidation pressure, $p$, of the expansive soil after different number of times of microbial treatment were obtained, as shown in Figure 4. For convenience, the consolidation pressures of the expansive soil in the figure are represented by the midpoints of $12.5-50 \mathrm{kPa}, 50-100 \mathrm{kPa}$, $100-200 \mathrm{kPa}, 200-400 \mathrm{kPa}$, and $400-800 \mathrm{kPa}$, respectively.

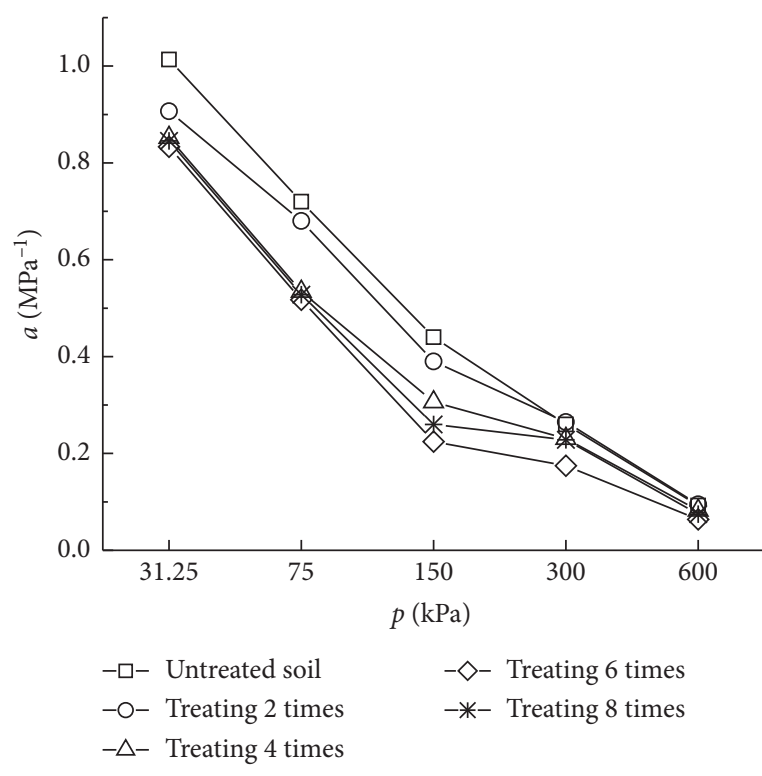

Figure 4: Relations between $a$ and $p$.

From Figure 4, it can be found that, under the same consolidation pressure, the coefficients of compressibility of the expansive soil samples after microbial improvement are all smaller than those of the untreated soil sample. Also, the slopes of the curve of the microbially treated soil samples are more or less similar to those of the untreated sample at low consolidation pressure, say less than $75 \mathrm{kPa}$; as the consolidation pressure increases, say over $150 \mathrm{kPa}$, the slopes of the curves of the microbially treated soil samples are then significantly reduced compared to those of the untreated soil sample. The above findings show that, as the consolidation pressure increases, the microbially treated soil samples become more and more difficult to be compressed due to the improvement of the MICP effect and also the increasing consolidation pressure. As a comparison, when it exceeds $150 \mathrm{kPa}$ to $600 \mathrm{kPa}$, the coefficient of compressibility of the untreated soil samples decreases dramatically, which indicates that the soil samples still undergo considerable compression deformation within this high-pressure range.

\subsection{Variation of Vertical Strain and Consolidation Pressure.} After the expansive soil samples were treated with microorganisms for a different number of times, the changes of the soil vertical strains with the increase of consolidation pressures are shown in Figure 5.

It can be known from Figure 5 that (1) in all soil samples, whether or not being improved, their vertical strains increase with the increase of the consolidation pressures; however, increase rates of the vertical strains gradually slow down, so the increase in the consolidation deformation gradually decreases; (2) under the same consolidation pressure, the vertical strain of the soil samples after microbial improvement is significantly lower than that of the unimproved soil samples; (3) at the same consolidation pressure, the number of microbial treatments increased to the sixth, and the vertical strains of the soil samples reduce to be minimum; continuous 


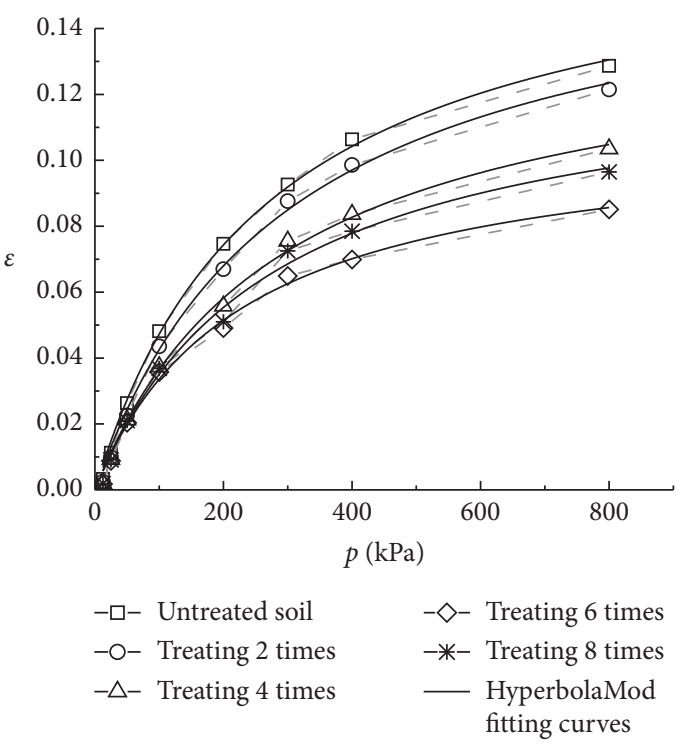

Figure 5: Relations between $\varepsilon$ and $p$. improvement of soil samples, say the $8^{\text {th }}$ time, results in the strain to rebound considerably.

The above three aspects can be explained as follows: on the one hand, as the consolidation pressure increases, the soil particles are rearranged and gradually compacted, and the soil coefficient of compressibility decreases, so the incremental amount of compression decreases; on the other hand, the generated calcium carbonate precipitates in the microbially treated expansive soil samples are cemented on the surface of the soil particles or filled in the pores of the soil, which provides additional skeleton strength to the soil, so the compressive strength of the soil is increased, resulting in a decrease in the incremental vertical strain of the soil. The changes between the vertical strains and the consolidation pressures shown in Figure 5 adequately show that the compression characteristics of the expansive soil after microbial improvement have been significantly improved.

By observing the curve of the vertical strain and consolidation pressure in Figure 5, the hyperbolic function can be used for fitting. The relationship between the vertical strain and the consolidation pressure before and after the improvement of the expansive soil can be obtained:

$$
\varepsilon=\frac{p}{a+b p}
$$

where $\varepsilon$ indicates the vertical strain under consolidation pressure, $p$, and $a$ and $b$ are fitting parameters as listed in Table 4.

From equation (2), it is straightforward to obtain the inverse of the pressure-dependent instantaneous elastic modulus, $1 / E_{t}$ :

$$
\frac{1}{E_{t}}=\frac{\mathrm{d} \varepsilon}{\mathrm{d} p}=\frac{a}{(a+b p)^{2}} .
$$

From equations (2) and (3), the physical meanings of the parameters $a$ and $b$ are clear:

(1) $1 / a$ indicates the initial slope of the strain to the consolidation pressure:

$$
\frac{1}{E_{0}}=\frac{1}{a} .
$$

In another word, $a$ itself means the initial elastic modulus, $E_{0}$.

(2) $1 / b$ represents the asymptotic strain when $p$ increases to infinity:

$$
\varepsilon_{u l t}=\frac{1}{b}
$$

Also, from equation (2), the consolidation pressure can be expressed as a function of the vertical strain:

$$
p=\frac{a \varepsilon}{1-b \varepsilon} .
$$

Substitute equation (6) into (3) to obtain

$$
\frac{1}{E_{t}}=\frac{(1-b \varepsilon)^{2}}{a} \text {. }
$$

Therefore, the relationship between the vertical strain of microbially modified expansive soil and the consolidation pressure can also be expressed in the incremental form as follows:

$$
\mathrm{d} \varepsilon=\frac{(1-b \varepsilon)^{2}}{a} \mathrm{~d} p .
$$

Also, from Table 4, it is found that the coefficient $a$ gradually increases with the increase in the number of microbial treatments, while $b$ increases till the $6^{\text {th }}$ treatment and then decreases at the $8^{\text {th }}$ treatment.

3.4. Preconsolidation Pressure of Microbially Modified Expansive Soil. As another critical soil index, preconsolidation pressure normally reflects the stress history of the soil. The pressure is normally determined by Casagrande's empirical method. Nevertheless, it is challenging to determine the point of minimum radius of curvature, so as to follow Casagrande's empirical method.

Alternatively, we adopt $\ln (1+e)-\lg p$, the double logarithm method, i.e., the compression curve of the expansive soil is represented by double straight lines, and the intersection of the two straight lines is considered to be the preconsolidation pressure $p_{c}$. The double logarithm method was first proposed by Butterfield [44]. Afterwards, Onitsuka et al. [45] and Hong and Onitsuka [46] validated the method through a large number of experiments. It can be seen from Figure 6 that the bilogarithmic characteristic of each compression curve is significant, in line with the bilinear 


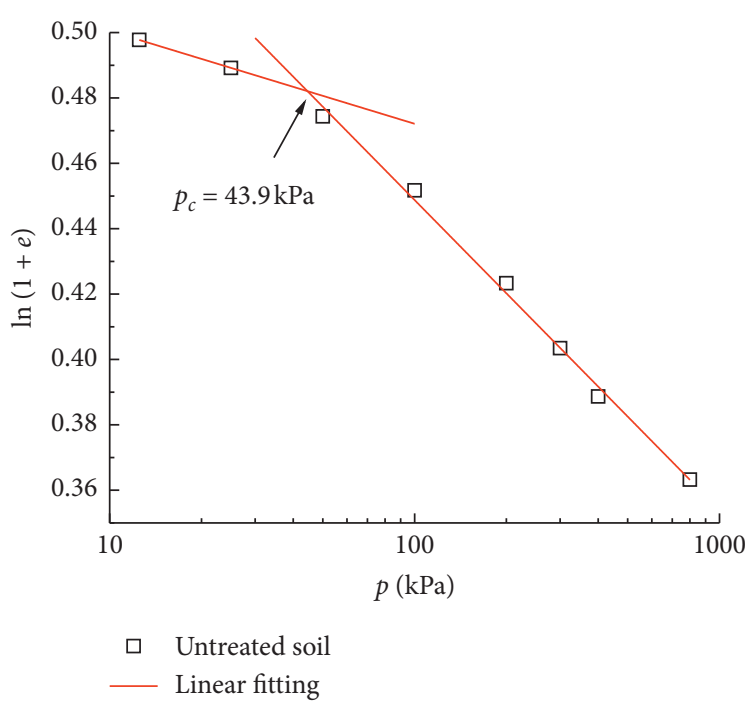

(a)

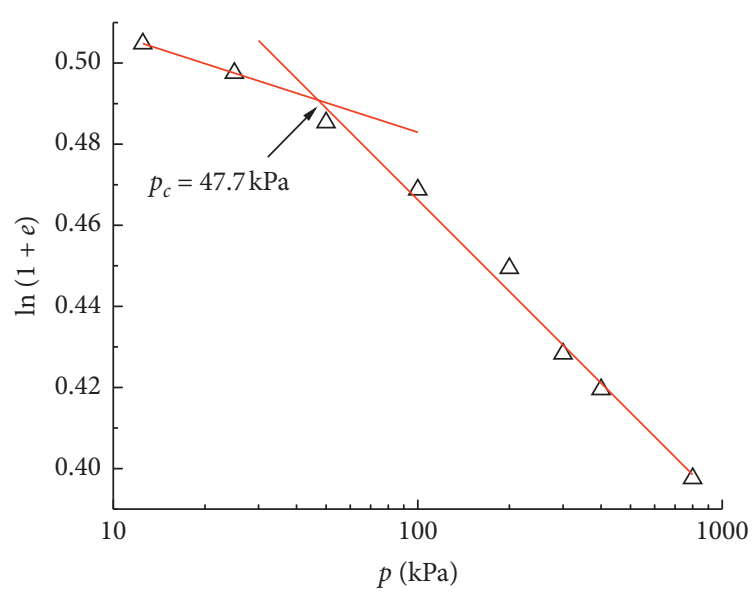

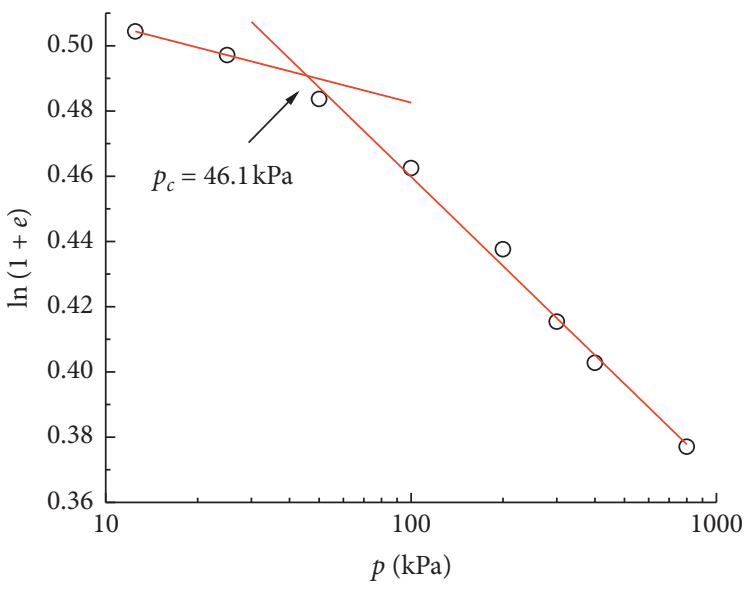

○ Treating 2 times

__ Linear fitting

(b)

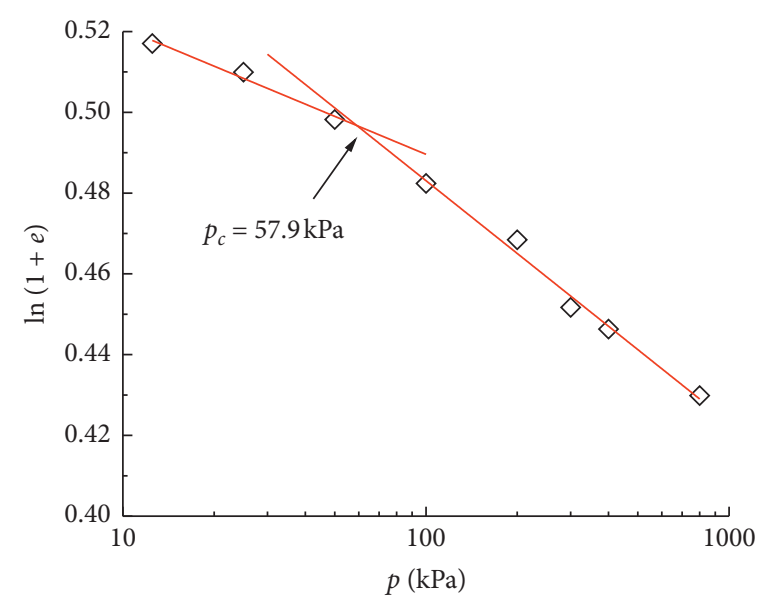

$\diamond \quad$ Treating 6 times

Linear fitting

(c)

(d)

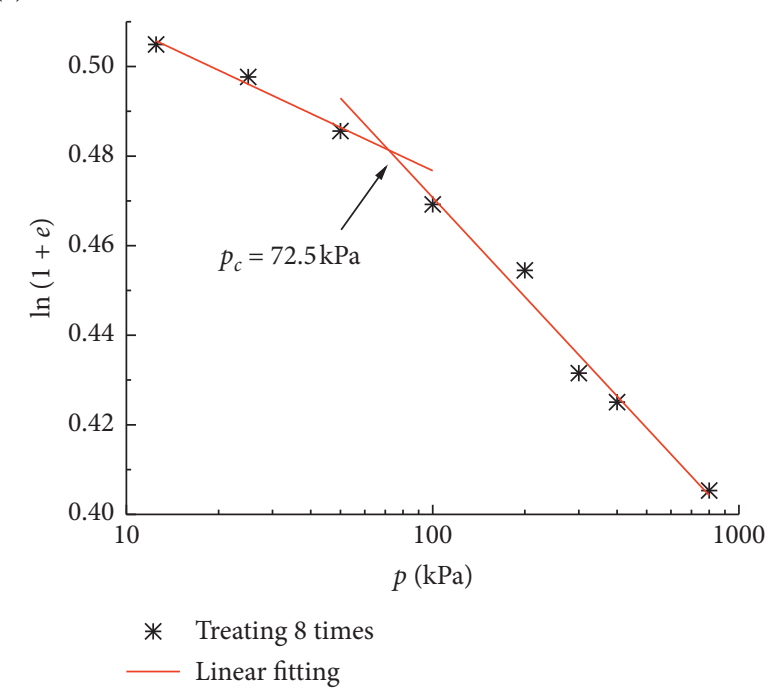

(e)

FIGURE 6: compression curve $(\ln (1+e)-\operatorname{lgp})$ of microbially-treated expansive soil samples. 
TABLE 4: Fitting parameters.

\begin{tabular}{lccr}
\hline Soil samples & $a$ & $b$ & $R^{2}$ \\
\hline Untreated soil & 1543.202 & 5.735 & 0.997 \\
Treating 2 times & 1761.237 & 5.902 & 0.996 \\
Treating 4 times & 2035.680 & 7.000 & 0.996 \\
Treating 6 times & 2069.820 & 9.086 & 0.993 \\
Treating 8 times & 2087.056 & 7.628 & 0.992 \\
\hline
\end{tabular}

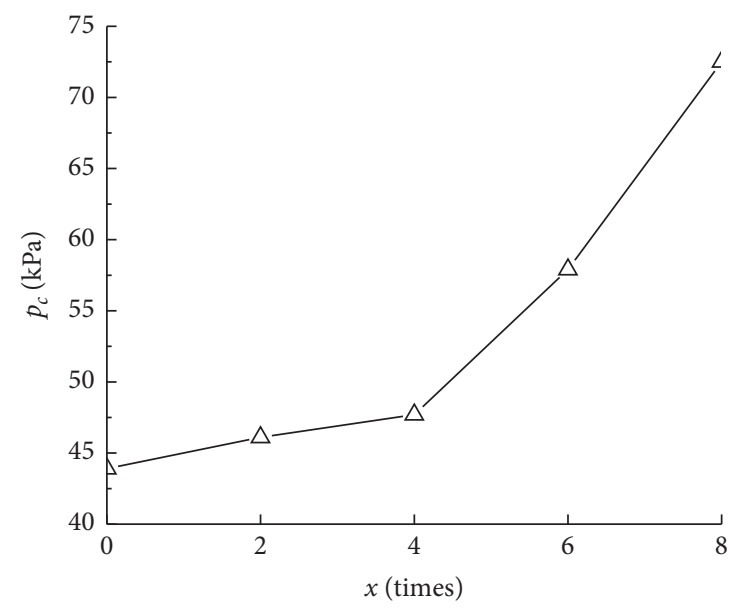

FIGURE 7: Relationship between $p c$ and times of treatment, $x$.

rule, and the inflection point $\left(p_{c}\right)$ value of each curve can be straightforwardly identified.

As shown in Figure 7, it is obvious that the $p_{c}$ values of the expansive soil improved by microorganisms are higher than those of the unimproved; the $p_{c}$ value of the expansive soil increases with the number of treatments; particularly, a dramatical increase is found after 4 times of microbial treatment. This phenomenon shows that the microbial treatment has a significant effect on the increase of $p_{c}$ in the expansive soil. However, it should be noted that the change of the inflection point $p_{c}$ shown in Figures 6 and 7 is obviously not the "real" preconsolidation pressure, but a reflection of the structural strength.

The increase of the structural strength can be illustrated as follows: the microorganisms which entered the pores of the soil were mineralized to generate calcium carbonate precipitates that were found to be mainly calcite crystals [36]. These crystals were generated in irregular particles on the surface and gaps of the soil particles, wrapping up and tightly connecting the soil particles. As a result, the contact area between the soil particles is increased and the connection capacity between the soil particles is enhanced, which cause more integrated and denser internal structure of the soil. Therefore, the structural strength of the soil is largely improved.

Furthermore, in Figures 6(a)-6(e), by fitting lines of the compression curves after $p_{c}$, the slopes correspond to the (post- $p_{c}$ ) normal compression lines. These slopes are obtained under the double logarithmic coordinates of Figure 6, similar to the compression index in the $e$ - $p$ curve, hence reflecting the soil compression characteristics. The results of each slope are shown in Figure 8. It can be seen that (1) when the consolidation pressure reaches the inflection point, the slope of the compression curve of the expansive soil modified by microorganisms is less than that of the unmodified soil; (2) the slope of the normal compression curve decreases first and then increases with the increase of the number of treatments; in particular, the slope is the smallest when the microorganisms are treated 6 times.

The above two findings, again, show that the compression properties of the expansive soil after microbial treatment have been improved. Nevertheless, excessive treatment (such as the eight treatments in our study) is not conducive to improving the compression performance of the expansive soil when the compressive stress is higher than $p_{c}$. The reason is that too many treatments mean excessive grinding of the soil samples, which may severely disrupt some cementation of the soil and produce a large amount of microparticles to small particles, minimizing the amount of medium to large particles. In addition, excessive treatments of the soil may result in a decrease in the precipitation efficiency of calcium carbonate between soil particles. This leads to significant changes of the structure of the particles and pores of the expansive soil. Such changes in the internal structure of the soil are very complicated and need further observation of the development of calcite crystals.

\section{Microstructural Analysis}

Through using the scanning electron microscope (SEM), the microstructure characteristics of the soil sample under the appropriate magnification were observed, as shown in 


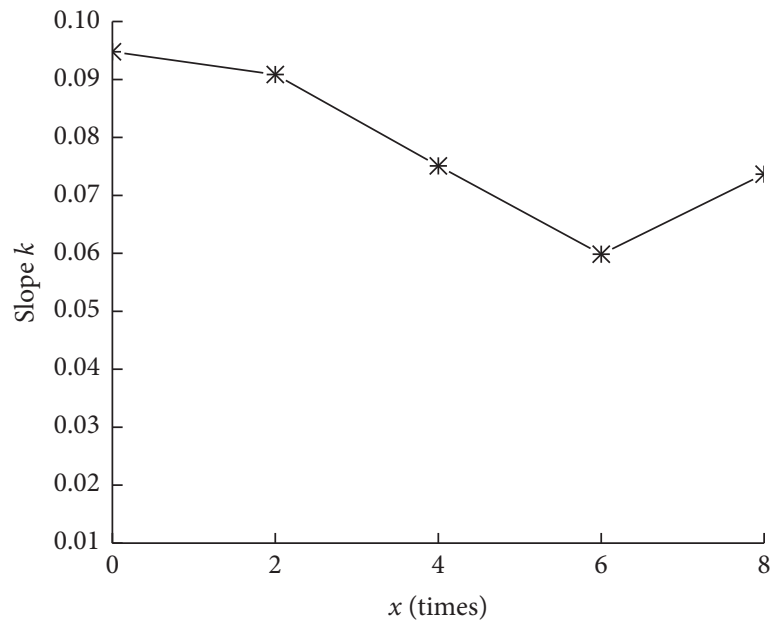

FiguRE 8: Relationship between the slope of the compression curve and $x$.
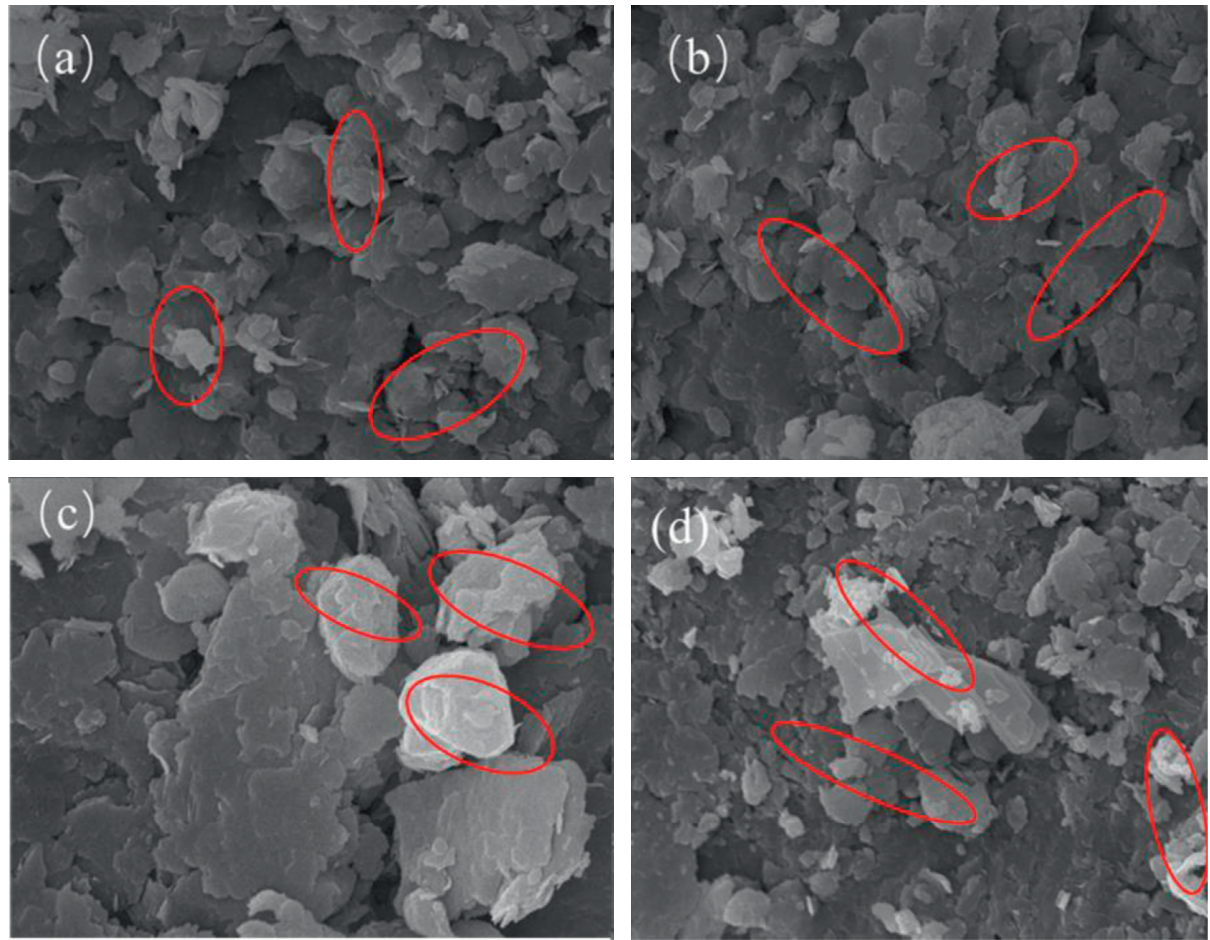

Figure 9: SEM micrographs of (a) 2 times, (b) 4 times, (c) 6 times, and (d) 8 times. Some crystals are marked with circles.

Figure 9. As can be seen from the figure, a number of irregularly shaped, angular crystals are distributed around the soil particles. These crystals are calcium carbonate precipitates produced by microbial mineralization. They wrap on the surface of soil particles, cement the soil particles, and improve the stability of the soil particles. This helps to understand the mechanism of the improved compressibility and structural strength of the expansive soil. By further observing Figures 9(a)-9(d), it is found that the degree of crystal development and morphology and cementation effect vary with the number of treatments. This shows that different treatment times have an impact on the mineralization of microorganisms. However, only based on the current preliminary SEM results, the relationship between treatment times and mineralization is not significant enough. Therefore, future work needs to be continued from a microscopic perspective to further observe the shape of the crystal and the effect of the interaction between the crystal and the soil particles.

\section{Mechanism Analysis of Microbial Improvement of Compression Characteristics of the Expansive Soil}

5.1. Filling Effect. In the process of calcium carbonate precipitation induced by the microorganisms, some crystalline and 
noncrystalline inorganic compound precipitates are produced, and their main component is calcium carbonate colloid. The microbial process that produces these colloids, followed by colloidal crystallization and solidification, is also called microbial mineralization. From our study, this mineralization process in the expansive soil can be efficiently completed using Bacillus pasteurii. After the mineral compounds are mineralized, they precipitate in the pores between the soil particles so that a large amount of pores are filled, which results in a decrease in soil porosity and an increase in soil compactness.

5.2. Cementing Effect. In the process of MICP, calcium carbonate colloids are precipitated on the surface of the soil particles as shown in Figure 9. The soil particles are cemented with each other, and they are firmly connected to each other. In this process, on the one hand, because the microorganisms enter the soil pores and undergo mineralization, the fine particles (such as colloidal particles and clay particles) in the soil are consolidated with each other to form aggregates and become coarse particles (such as silt and sand). As a result, the content of colloidal and clay particles in the soil decreases, the content of silt and sand particles increases, and the particle grading of the expansive soil changes. On the other hand, due to the cementation of the soil particles, the connection between the soil particles is enhanced. Therefore, the structural strength of the soil is improved, and the ability of the soil to resist external deformation is significantly improved.

\section{Conclusions}

Most of the current research studies focus on reducing the expansive properties of the expansive soil; however, after the improvement of the soil, the research on how the compressibility of the expansive soil will affect is rare. In this paper, through the experimental study of the compression characteristics of the improved expansive soil by MICP technology, the effects of different microbial contents (via the number of treatments) on the compression characteristics of the expansive soil were investigated, and the microstructure of mineralization was analyzed. The main conclusions obtained in this paper are as follows:

(1) It is feasible to improve the compression characteristics of the expansive soil based on the MICP technology by adopting a suitable treatment method. After the microbial improvement, the coefficient of compressibility of the expansive soil was significantly reduced, and the soil compressibility changed from high to low level. Among them, in our study, the compressibility improvement effect was the best at 6 times of microbial treatment.

(2) After microbial improvement, the relationship between the soil vertical strain and consolidation pressure can be simply and accurately represented by a hyperbolic function that is controlled by two physically meaningful parameters $a$ and $b$.
(3) As the numbers of treatment increase, the preconsolidation pressure (here reflecting the structural strength of the expansive soil) increases significantly. This increase in soil strength is closely related to changes in the internal structure of the soil body.

(4) We observe the existence of crystals between soil particles by SEM test and validate the microbial mineralization based on MICP.

In practice, the expansive soil treated by MICP might also be used with other granular soils [47] and mixtures $[48,49]$ to improve the performance of embankments, which is worthy of further study.

\section{Data Availability}

The data that support the plots within this paper and other findings of this study are available from the corresponding author upon reasonable request.

\section{Conflicts of Interest}

The authors declare that they have no conflicts of interest.

\section{Acknowledgments}

The work described in this paper was supported by a grant from the National Natural Science Foundation of China (Project no. 50978097).

\section{References}

[1] J. James and P. K. Pandian, "Plasticity, swell-shrink, and microstructure of phosphogypsum admixed lime stabilized expansive soil," Advances in Civil Engineering, vol. 2016, Article ID 9798456, 10 pages, 2016.

[2] Y. Liu, Y. Su, A. Namdar, G. Zhou, Y. She, and Q. Yang, "Utilization of cementitious material from residual rice husk ash and lime in stabilization of expansive soil," Advances in Civil Engineering, vol. 2019, Article ID 5205276, 17 pages, 2019.

[3] B. R. Phanikumar and T. V. Nagaraju, "Effect of fly ash and rice husk ash on index and engineering properties of expansive clays," Geotechnical and Geological Engineering, vol. 36, no. 6, pp. 3425-3436, 2018.

[4] J. M. Bian, L. Jiang, and B. T. Wang, "Strength test of expansive soil improved by lime," Journal of Chang'an University, vol. 33, pp. 38-43, 2013.

[5] P. Voottipruex and P. Jamsawang, "Characteristics of expansive soils improved with cement and fly ash in northern Thailand," Geomechanics and Engineering, vol. 6, no. 5, pp. 437-453, 2014.

[6] W. Deng and Y. Wang, "Investigating the factors affecting the properties of coral sand treated with microbially induced calcite precipitation," Advances in Civil Engineering, vol. 2018, Article ID 9590653, 6 pages, 2018.

[7] R. Gui, Y.-X. Pan, D.-X. Ding, Y. Liu, and Z.-J. Zhang, "Experimental study on the fine-grained uranium tailings reinforced by MICP," Advances in Civil Engineering, vol. 2018, Article ID 2928985, 10 pages, 2018.

[8] J. K. Mitchell and J. C. Santamarina, "Biological considerations in geotechnical engineering," Journal of Geotechnical 
and Geoenvironmental Engineering, vol. 131, no. 10, pp. 1222-1233, 2005.

[9] W. De Muynck, N. De Belie, and W. Verstraete, "Microbial carbonate precipitation in construction materials: a review," Ecological Engineering, vol. 36, no. 2, pp. 118-136, 2010.

[10] M. Umar, K. A. Kassim, and K. T. Ping Chiet, "Biological process of soil improvement in civil engineering: a review," Journal of Rock Mechanics and Geotechnical Engineering, vol. 8, no. 5, pp. 767-774, 2016.

[11] J. T. DeJong, K. Soga, E. Kavazanjian et al., "Biogeochemical processes and geotechnical applications: progress, opportunities and challenges," Géotechnique, vol. 63, no. 4, pp. 287-301, 2013.

[12] X. Sun, L. Miao, T. Tong, and C. Wang, "Improvement of microbial-induced calcium carbonate precipitation technology for sand solidification," Journal of Materials in Civil Engineering, vol. 30, Article ID 4018301, 2018.

[13] C. Dupraz, R. P. Reid, O. Braissant, A. W. Decho, R. S. Norman, and P. T. Visscher, "Processes of carbonate precipitation in modern microbial mats," Earth-Science Reviews, vol. 96, no. 3, pp. 141-162, 2009.

[14] J. T. DeJong, M. B. Fritzges, and K. Nüsslein, "Microbially induced cementation to control sand response to undrained shear," Journal of Geotechnical and Geoenvironmental Engineering, vol. 132, no. 11, pp. 1381-1392, 2006.

[15] M. G. Gomez, C. M. R. Graddy, J. T. DeJong, and D. C. Nelson, "Biogeochemical changes during bio-cementation mediated by stimulated and augmented ureolytic microorganisms," Scientific Reports, vol. 9, Article ID 11517, 2019.

[16] D. Gat, M. Tsesarsky, D. Shamir, and Z. Ronen, “Accelerated microbial-induced CaCO,” Biogeosciences, vol. 11, pp. 25612569, 2014.

[17] V. Achal and X. L. Pan, "Characterization of urease and carbonic anhydrase producing bacteria and their role in calcite precipitation," Current Microbiology, vol. 62, pp. 894-902, 2011.

[18] V. S. Whiffin, Microbial $\mathrm{CaCO}_{3}$ Precipitation for the Production of Biocement, Murdoch University, Perth, Australia, 2004.

[19] A. M. Sharaky, N. S. Mohamed, M. E. Elmashad, and N. M. Shredah, "Application of microbial biocementation to improve the physico-mechanical properties of sandy soil," Construction and Building Materials, vol. 190, pp. 861-869, 2018.

[20] L. Liu, H. Liu, A. W. Stuedlein, T. M. Evans, and Y. Xiao, "Strength, stiffness, and microstructure characteristics of biocemented calcareous sand," Canadian Geotechnical Journal, vol. 56, pp. 1502-1513, 2019.

[21] M. Khaleghi and M. Rowshanzamir, "Biologic improvement of a sandy soil using single and mixed cultures: a comparison study," Soil \& Tillage Research, vol. 186, pp. 112-119, 2019.

[22] Z. Wang, N. Zhang, J. Ding, C. Lu, and Y. Jin, "Experimental study on wind erosion resistance and strength of sands treated with microbial-induced calcium carbonate precipitation," Advances in Materials Science and Engineering, vol. 2018, Article ID 3463298, 10 pages, 2018.

[23] H. L. Liu, "Experimental study on dynamic characteristics of MICP cemented sand," Chinese Journal of Geotechnical Engineering, vol. 40, pp. 38-45, 2018.

[24] H. Canakci, W. Sidik, and I. H. Halil, "Effect of bacterial calcium carbonate precipitation on compressibility and shear strength of organic soil," Soils Found, vol. 55, pp. 1211-1221, 2015.
[25] V. Ivanov and J. Chu, "Applications of microorganisms to geotechnical engineering for bioclogging and biocementation of soil in situ," Reviews in Environmental Science and Biotechnology, vol. 7, pp. 139-153, 2008.

[26] J. Do, "Debonding of microbially induced carbonate precipitation-stabilized sand by shearing and erosion," International Journal of Geo-Engineering, vol. 17, pp. 429-438, 2019.

[27] J. F. Tang, "Development of microbially induced calcium carbonate precipitation technology in soil improvement," International Journal of Advanced Research and Technology, vol. 2, pp. 26-29, 2016.

[28] Y.-M. Kwon, I. Chang, M. Lee, and G.-C. Cho, "Geotechnical engineering behavior of biopolymer-treated soft marine soil," International Journal of Geo-Engineering, vol. 17, pp. 453-464, 2019.

[29] A. Almajed, H. K. Tirkolaei, E. Kavazanjian, and N. Hamdan, "Enzyme induced biocementated sand with high strength at low carbonate content," Scientific Reports, vol. 9, p. 1135, 2019.

[30] M. Burbank, "Geotechnical tests of sands following bioinduced calcite precipitation catalyzed by indigenous bacteria," Journal of Geotechnical \& Geoenvironmental Engineering, vol. 139, pp. 928-936, 2013.

[31] A. Gurbuz, Y. D. Sari, Z. N. Yuksekdag, and B. Cinar, "Cementation in a matrix of loose sandy soil using biological treatment method," African Journal of Biotechnology, vol. 10, pp. 7432-7440, 2011.

[32] A. Mahawish, A. Bouazza, and W. P. Gates, "Improvement of coarse sand engineering properties by microbially induced calcite precipitation," Geomicrobiology, vol. 35, pp. 887-897, 2018.

[33] B. C. Martinez, "Experimental optimization of microbiallnduced carbonate precipitation for soil improvement," Journal of Geotechnical \& Geoenvironmental Engineering, vol. 139, pp. 587-598, 2013.

[34] H. A. Keykha, A. Asadi, B. B. K. Huat, and S. Kawasaki, "Laboratory conditions for maximal calcium carbonate precipitation induced by Sporosarcina pasteurii and Sporosarcina aquimarina bacteria," Environmental Geotechnics, vol. 6, pp. 1-20, 2018.

[35] G. D. O. Okwadha and J. Li, "Optimum conditions for microbial carbonate precipitation," Chemosphere, vol. 81, pp. 1143-1148, 2010.

[36] A. A. Qabany, K. Soga, and C. Santamarina, "Factors affecting efficiency of microbially induced calcite precipitation," Journal of Geotechnical \& Geoenvironmental Engineering, vol. 138, pp. 992-1001, 2012.

[37] V. Achal and X. Pan, "Influence of calcium sources on microbially induced calcium carbonate precipitation by $\mathrm{Ba}-$ cillus sp. CR2," Biotechnology and Applied Biochemistry, vol. 173, pp. 307-317, 2014.

[38] M. P. Harkes, L. A. Van Paassen, J. L. Booster, V. S. Whiffin, and M. C. Van Loos-Drecht, "Fixation and distribution of bacterial activity in sand to induce carbonate precipitation for ground reinforcement," Ecological Engineering, vol. 36, pp. 112-117, 2010.

[39] J. F. Qian, Y. S. Yao, J. Li, H. B. Xiao, and S. P. Luo, "Resilient properties of soil-rock mixture materials: preliminary investigation of the effect of composition and structure," Materials, vol. 13, no. 7, p. 1658, 2020.

[40] C. Xia, S. Lv, M. B. Cabera, X. Wang, C. Zhang, and L. You, "Unified characterizing fatigue performance of rubberized asphalt mixtures subjected to different loading modes," Journal of Cleaner Production, vol. 249, 2020. 
[41] C. Lin, S. Lv, D. J, and F. Qu, "Laboratory investigation for the road performance of asphalt mixtures modified by rock asphalt/styrene butadiene rubber," Journal of Materials in Civil Engineering, vol. 33, 2021.

[42] P. Anbu, C.-H. Kang, Y.-J. Shin, and J.-S. So, Formations of Calcium Carbonate Minerals by Bacteria and its Multiple Applications, Springer International Publishing, New York City, NY, USA, 2016.

[43] T. Islam, Studying the Applicability of Biostimulated Calcite Precipitation in Stabilizing Expansive Soils, Boise State University, Boise, ID, USA, 2018.

[44] R. Butterfield, "A natural compression law for soils (anadvance on e-logp)," Geotechnique, vol. 29, pp. 469-480, 1979.

[45] K. Onitsuka, Z. Hong, Y. Hara, and S. Yoshitake, "Interpretation of oedometer test data for natural clays," Soils Found.vol. 35, pp. 61-70, 1995.

[46] Z. Hong and K. Onitsuka, "A method of correcting yield stress and compression index of ariake clays for sample disturbance," Soils and Foundations, vol. 38, pp. 211-222, 1998.

[47] Y. Yao, J. Ni, and J. Li, "Stress-dependent water retention of granite residual soil and its implications for ground settlement," Computers and Geotechnics, vol. 129, Article ID 103835, 2021.

[48] C. Liu, S. Lv, D. Jin, and F. Qu, "Laboratory investigation for the road performance of asphalt mixtures modified by rock asphalt/styrene butadiene rubber," Journal of Materials in Civil Engineering, vol. 33, 2020.

[49] S. Zhang, Y. Ronald, S. Pak, and J. Zhang, "Vertical timeharmonic coupling vibration of an impermeable, rigid, circular plate resting on a finite, poroelastic soil layer," Acta Geotechnica, vol. 2, pp. 1-25, 2020. 